\title{
COMPARATIVE STUDY OF THE LANTHANIDE (Ln) AND ACTINIDE (An) TRIFLATE COMPLEXES M(OTf $)_{n}$
}

\author{
M. Lemmouchi ${ }^{1}$, D. Hannachi ${ }^{1,2}$, N. Ouddai ${ }^{1}$ \\ ${ }^{1}$ Laboratoire Chimie des matériaux et des vivants: Activité, Réactivité, Université El-Hadj Lakhdar, Batna, Algeria \\ E-mail: ouddai_nadia@yahoo.fr \\ ${ }^{2}$ University Farhat Abbasse, Setif, Algeria
}

Received August, 05, 2014

\begin{abstract}
Theoretical studies on the lanthanide and actinide triflate complexes $\mathrm{M}(\mathrm{OTf})_{n}$ where $\mathrm{M}=\mathrm{La}$, $\mathrm{Ce}, \mathrm{Gd}, \mathrm{Yb}, \mathrm{Lu}, \mathrm{Th}, \mathrm{U}, \mathrm{Np}, \mathrm{Pu}, \mathrm{Am}, \mathrm{Cm}, \mathrm{Bk}$, and No; $n=3$ and 4, are carried out using functional density theory (DFT). The study of $\mathrm{An}(\mathrm{OTf})_{3}$ complexes showed that the three OTf groups are bidentate, generating a trigonal prism (TP). Two limiting structures of TP are observed; the most distorted is the thorium triflate $\mathrm{Th}(\mathrm{OTf})_{3}$ and the ideal one is $\mathrm{U}(\mathrm{OTf})_{3}$. The highest population contribution of $5 d$ orbital compared to $5 f$ orbital in $\mathrm{Th}-\mathrm{O}$ bond of $\mathrm{Th}(\mathrm{OTf})_{3}$ explains the distortion. The intramolecular rearrangement of the OTf ligands in $\mathrm{Ln}(\mathrm{OTf})_{3}$ generates two conformers. In $\mathrm{Yb}(\mathrm{OTf})_{3}$, the pseudo-eclipsed and the staggered conformations are stable and can be isolated.
\end{abstract}

DOI: $10.15372 / \mathrm{JSC} 20150806$

K e y w o r d s: triflate, lanthanide, actinide, coordination, intramolecular rearrangement.

\section{INTRODUCTION}

The importance of lanthanide and actinide triflates lays in the fact that the trivalent lanthanide (Ln) and actinide (An) ions exhibit strong analogies in their chemical properties and their differentiation is highly desirable and potentially useful in various areas $[1,2]$. The utility of lanthanide triflates has been clearly recognized in recent years [3], as Lewis acid catalysts in a variety of organic reactions, as well as precursors in inorganic and organometallic synthesis and they are also used in the nuclear industry [4 ]. In coordination chemistry, the selective complexation of actinides (III) and lanthanides (III) with efficient extracting molecules is an important problem for both fundamental aspects and applications, in particular in the partitioning of spent nuclear fuels [5,6]. Generally, the actinidebased compounds are of great current interest not only for their relevance in the nuclear industry and the associated environmental concerns but also for their rich structural chemistry and attractive magnetic and electrochemical properties, which could lead to the development of new functional materials [7]. According to the recent available data several triflate actinide compounds have been reported [ 8-11 ]. Our study fits into the research focus of differentiation between structural properties of actinides and lanthanides. The analysis of actinide and lanthanide triflates family of the type $\mathrm{M}(\mathrm{OTf})_{n}$, where $\mathrm{M}=\mathrm{La}, \mathrm{Ce}, \mathrm{Gd}, \mathrm{Yb}, \mathrm{Lu}, \mathrm{Th}, \mathrm{U}, \mathrm{Np}, \mathrm{Pu}, \mathrm{Am}, \mathrm{Cm}, \mathrm{Bk}$, and No; $n=3$ and 4 has the main objective; rational study of coordination mode between the triflate ligand and the metal. This theoretical approach uses quantum calculations based on the theory of functional density.

\section{COMPUTATIONAL DETAILS}

Quantum calculations were carried out using the Amsterdam Functional Density program developed by Baerends and co-workers [12 ]. Electron correlation was treated within general gradient ap-

(C) Lemmouchi M., Hannachi D., Ouddai N., 2015 
proximation with the functional PW91 [13]. The atom electronic configurations were described by a triple $\xi$ Slater type orbital (STO) basis set, $2 s$ for $\mathrm{C}$ and $\mathrm{F}, 2 p$ for and $\mathrm{O}, 3 s$ and $3 p$ for $\mathrm{S}$, augmented with $3 d$ single- $\xi$ polarization functions for $\mathrm{C}, \mathrm{F}$, and $\mathrm{O}$, and $4 p$ single- $\xi$ polarization functions for $\mathrm{S}$. The atomic basic set of the lanthanide and actinide atoms is the following: a triple $\xi$-STO for the outer $5 f, 4 f, 5 d$ and $6 s$ orbitals, a frozen core approximation for the shells of lower energy. Relativistic corrections were taken into account with the use of the relativistic (ZORA) method [ 14 ]. The integration parameter and the energy convergence criterion were set to be 6 and $10^{-3}$ a.u., respectively.

\section{RESULTS AND DISCUSSION}

The structural arrangement of actinide triflates were comparable to those obtained with the lanthanide triflates [15]. The spatial arrangement of atoms in $\mathrm{An}(\mathrm{OTf})_{3}$ forms a trigonal prism with coordination number equals to six and ligands OTf are bidentate.

Geometric descriptors. The structural parameters of $\mathrm{An}(\mathrm{OTf})_{3}$. The geometric parameter of $\mathrm{An}(\mathrm{OTf})_{3}$ are summarized in Table 1. The lengths of the $\mathrm{An}-\mathrm{O}$ bond are between $2.37 \AA$ and $2.46 \AA$, these values are in the range of those obtained experimentally by other research teams [16-21]; for example in $\left[\mathrm{U}(\mathrm{OTf})_{3}\left(\mathrm{OPPh}_{3}\right)_{4}\right][22]$ and $\left[\mathrm{U}\left(\mathrm{C}_{5} \mathrm{H}_{5}\right)_{3}(\mathrm{OTf})(\mathrm{CN} t \mathrm{Bu})\right]$ complexes [23], where the ligand OTf is monodentate, the bond length $\mathrm{U}-\mathrm{O}$ are $2.446 \AA$ and $2.485 \AA$, respectively. In $\left[\mathrm{U}\left(\mathrm{C}_{5} \mathrm{Me}_{5}\right)_{2}(\mathrm{OTf})_{2}\left(\mathrm{H}_{2} \mathrm{O}\right)\right][22]$ the $\mathrm{U}-\mathrm{O}$ are $2361 \AA$ and $2401 \AA$. The difference between the distances $(\mathrm{An}-\mathrm{O})$ is dependent on the difference of ionic radii of the metal centers and their electronegativities proposed by Allerd and Rochow [24]. All distances between the actinide and the oxygen atoms in $\mathrm{U}(\mathrm{OTf})_{3}$ and $\mathrm{No}(\mathrm{OTf})_{3}$ compounds are equidistant $(\mathrm{U}-\mathrm{O}=2.41 \AA)$ and $(\mathrm{No}-\mathrm{O}=2.42 \AA)$. In addition, the angles SAnS ( $\mathrm{An}=\mathrm{U}$ and No) are $120^{\circ}$. The distribution of the three atoms of sulfur relative to the fixed position of the metal center; form an equilateral triangular pyramid (the triangular base (S1-S2-S3)) (Scheme 1).
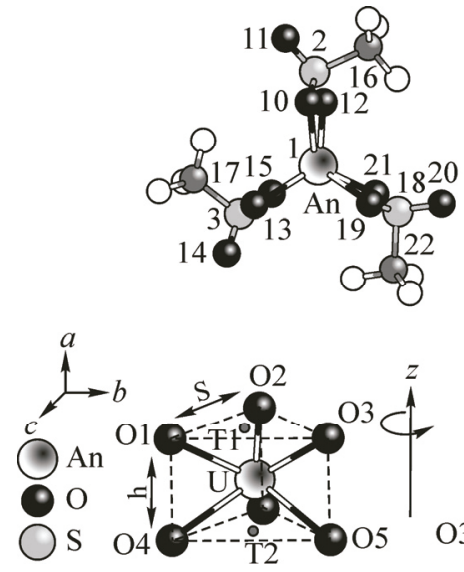
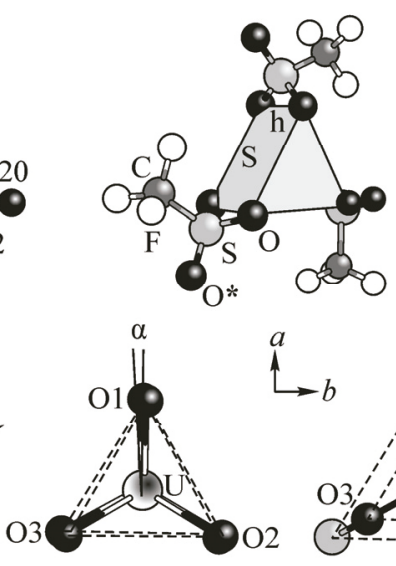

Scheme 1. The prism trigonal geometry and the ideal one of $\mathrm{U}(\mathrm{OTf})_{3}$

Classification of the actinide trigonal prism geometries. The coordination sphere of actinide creates with the six oxygen atoms two triangular pyramids, the upper one $\mathrm{O}_{10}-\mathrm{O}_{13}-\mathrm{O}_{19}$ and the lower one $\mathrm{O}_{12}-\mathrm{O}_{15}-\mathrm{O}_{21}$, these summits form trigonal prism (TP) geometry. This TP crystal is characterized with a side ridge value $(s)$ and inter-triangular separation value $(h)$ (Scheme 1) [26].

Ideal trigonal prism of $\mathbf{U}(\mathbf{O T f})_{3}$, both triangular bases of the trigonal prism geometry of $\mathrm{U}(\mathrm{OTf})_{3}$ are superposed and this compound has a twist angle $\alpha=1^{\circ}$, only one inter-triangular separation $(h)$ value $2.40 \AA$ and one side ridge value $(s) 3.62 \AA$. The uranium atom is surrounded by three sulfur atoms forming an angle of $120^{\circ}$ (Scheme 1 and Table 1).

Exceptional trigonal prism of $\mathbf{T h}(\mathbf{O T f})_{3}$. The geometry of thorium triflate has a peculiarity in the arrangement of the three ligands OTf. Two are in two parallel planes; the third is placed in the perpendicular plane (Scheme 2). This geometry is characterized by three values of the side ridge $(S 1=2.40 \AA, S 2=3.41 \AA$, and $S 3=3.75 \AA)$, two values of inter-triangular separation $\left(h_{1}=2.41 \AA\right.$ and 
$\mathrm{T} \mathrm{a} \mathrm{b} 1$ e 1

Main geometry parameters of $\mathrm{An}(\mathrm{OTf})_{3}$ compounds

\begin{tabular}{|c|c|c|c|c|c|c|c|c|}
\hline $\operatorname{An}(\mathrm{OTf})_{3}$ & Th & $\mathrm{U}$ & $\mathrm{Np}$ & $\mathrm{Pu}$ & $\mathrm{Am}$ & $\mathrm{Cm}$ & $\mathrm{Bk}$ & No \\
\hline \multicolumn{9}{|c|}{ An-O bond lengths $(\AA)$} \\
\hline $\mathrm{An}-\mathrm{O} 10$ & 2.45 & 2.41 & 2.41 & 2.39 & 2.39 & 2.40 & 2.39 & 2.42 \\
\hline $\mathrm{An}-\mathrm{O} 12$ & 2.45 & 2.41 & 2.40 & 2.42 & 2.42 & 2.38 & 2.38 & 2.42 \\
\hline $\mathrm{An}-\mathrm{O} 13$ & 2.46 & 2.41 & 2.41 & 2.40 & 2.38 & 2.40 & 2.39 & 2.42 \\
\hline $\mathrm{An}-\mathrm{O} 15$ & 2.46 & 2.41 & 2.42 & 2.41 & 2.40 & 2.40 & 2.38 & 2.42 \\
\hline $\mathrm{An}-\mathrm{O} 19$ & 2.43 & 2.41 & 2.42 & 2.42 & 2.42 & 2.38 & 2.37 & 2.42 \\
\hline $\mathrm{An}-\mathrm{O} 21$ & 2.46 & 2.41 & 2.41 & 2.39 & 2.39 & 2.40 & 2.39 & 2.42 \\
\hline \multicolumn{9}{|c|}{ An-S distances $(\AA)$} \\
\hline $\mathrm{An}-\mathrm{S} 2$ & 3.08 & 3.03 & 3.01 & 3.01 & 3.01 & 3.00 & 2.98 & 3.01 \\
\hline $\mathrm{An}-\mathrm{S} 3$ & 3.09 & 3.03 & 3.02 & 3.01 & 3.00 & 3.00 & 2.98 & 3.01 \\
\hline $\mathrm{An}-\mathrm{S} 18$ & 3.06 & 3.03 & 3.02 & 3.01 & 3.01 & 3.00 & 2.99 & 3.01 \\
\hline \multicolumn{9}{|c|}{ An-O - distances $(\AA)$} \\
\hline $\mathrm{An}-\mathrm{O} 11$ & 4.30 & 4.22 & 4.21 & 4.23 & 4.23 & 4.19 & 4.19 & 4.20 \\
\hline $\mathrm{An}-\mathrm{O} 14$ & 4.30 & 4.24 & 4.22 & 4.21 & 4.20 & 4.21 & 4.19 & 4.21 \\
\hline $\mathrm{An}-\mathrm{O} 20$ & 4.25 & 4.23 & 4.25 & 4.20 & 4.20 & 4.24 & 4.22 & 4.21 \\
\hline \multicolumn{9}{|c|}{$\mathrm{S}-\mathrm{O}$ bond lengths $(\AA)$} \\
\hline $\mathrm{S} 2-\mathrm{O} 10$ & 1.52 & 1.52 & 1.52 & 1.52 & 1.52 & 1.51 & 1.51 & 1.50 \\
\hline $\mathrm{S} 2-\mathrm{O} 12$ & 1.52 & 1.52 & 1.52 & 1.51 & 1.51 & 1.52 & 1.51 & 1.50 \\
\hline $\mathrm{S} 3-\mathrm{O} 13$ & 1.52 & 1.52 & 1.52 & 1.52 & 1.52 & 1.51 & 1.51 & 1.50 \\
\hline $\mathrm{S} 3-\mathrm{O} 15$ & 1.52 & 1.52 & 1.52 & 1.52 & 1.51 & 1.51 & 1.51 & 1.50 \\
\hline $\mathrm{S} 18-\mathrm{O} 19$ & 1.52 & 1.52 & 1.51 & 1.51 & 1.52 & 1.51 & 1.51 & 1.50 \\
\hline $\mathrm{S} 18-\mathrm{O} 21$ & 1.51 & 1.52 & 1.52 & 1.52 & 1.51 & 1.51 & 1.51 & 1.50 \\
\hline \multicolumn{9}{|c|}{$\mathrm{S}-\mathrm{C}$ bond lengths $(\AA)$} \\
\hline $\mathrm{S} 2(3,18)-\mathrm{C} 16(17,22)$ & 1.90 & 1.89 & 1.89 & 1.89 & 1.89 & 1.89 & 1.89 & 1.89 \\
\hline \multicolumn{9}{|c|}{$\angle \mathrm{SAnS}$ angles (deg.) } \\
\hline $\mathrm{S} 2-\mathrm{An}-\mathrm{S} 3$ & 112 & 120 & 119 & 123 & 128 & 113 & 116 & 120 \\
\hline $\mathrm{S} 3-\mathrm{An}-\mathrm{S} 18$ & 131 & 120 & 121 & 121 & 118 & 116 & 118 & 120 \\
\hline $\mathrm{S} 18-\mathrm{An}-\mathrm{S} 2$ & 117 & 120 & 120 & 116 & 114 & 131 & 126 & 120 \\
\hline \multicolumn{9}{|c|}{$\angle \mathrm{OAnO}$ angles (deg.) } \\
\hline $\mathrm{O} 10-\mathrm{An}-\mathrm{O} 12$ & 58.5 & 59.9 & 60.1 & 60.0 & 60.0 & 60.10 & 60.3 & 59.5 \\
\hline $\mathrm{O} 13-\mathrm{An}-\mathrm{O} 15$ & 58.4 & 59.6 & 59.7 & 60.1 & 60.2 & 60.00 & 60.6 & 59.5 \\
\hline $\mathrm{O} 19-\mathrm{An}-\mathrm{O} 21$ & 58.8 & 59.7 & 57.7 & 60.0 & 59.9 & 60.10 & 60.4 & 59.5 \\
\hline \multicolumn{9}{|c|}{$\angle \mathrm{OSO}$ angles (deg.) } \\
\hline $\mathrm{O} 10-\mathrm{S} 2-\mathrm{O} 12$ & 103 & 104 & 105 & 105 & 105 & 105 & 105 & 106 \\
\hline $\mathrm{O} 13-\mathrm{S} 3-\mathrm{O} 15$ & 103 & 104 & 105 & 105 & 105 & 105 & 105 & 106 \\
\hline $\mathrm{O} 19-\mathrm{S} 18-\mathrm{O} 21$ & 104 & 104 & 105 & 105 & 105 & 105 & 105 & 106 \\
\hline \multicolumn{9}{|c|}{$\angle$ AnOSO angles (deg.) } \\
\hline $\mathrm{An}-\mathrm{O} 10-\mathrm{S} 2-\mathrm{O} 12$ & 0.81 & 0.70 & 0.48 & 1.25 & 0.89 & 0.83 & 0.006 & 1.43 \\
\hline $\mathrm{An}-\mathrm{O} 13-\mathrm{S} 3-\mathrm{O} 15$ & 0.25 & 0.27 & 0.78 & 0.30 & 0.61 & 0.52 & 0.34 & 1.29 \\
\hline $\mathrm{An}-\mathrm{O} 19-\mathrm{S} 18-\mathrm{O} 21$ & 1.47 & 0.80 & 1.42 & 1.48 & 1.59 & 3.35 & 1.90 & 1.28 \\
\hline \multicolumn{9}{|c|}{ Trigonal prism geometry parameters } \\
\hline S: side ridge value, $\AA$ & $2.40,3.41,3.75$ & 3.62 & $3.66,3.71$ & $3.60,3.77$ & $3.53,3.79$ & $3.49,3.81$ & $3.53,3.72$ & $3.72,3.87$ \\
\hline $\begin{array}{l}h \text { : inter-triangular sepa- } \\
\text { ration, } \AA\end{array}$ & $2.41,3.55$ & 2.40 & 2.41 & 2.41 & 2.41 & 2.40 & 2.40 & 2.41 \\
\hline$\alpha$ : twist angle, deg. & 3 & 1 & 18 & 21 & 20 & 10 & 14 & 28 \\
\hline
\end{tabular}



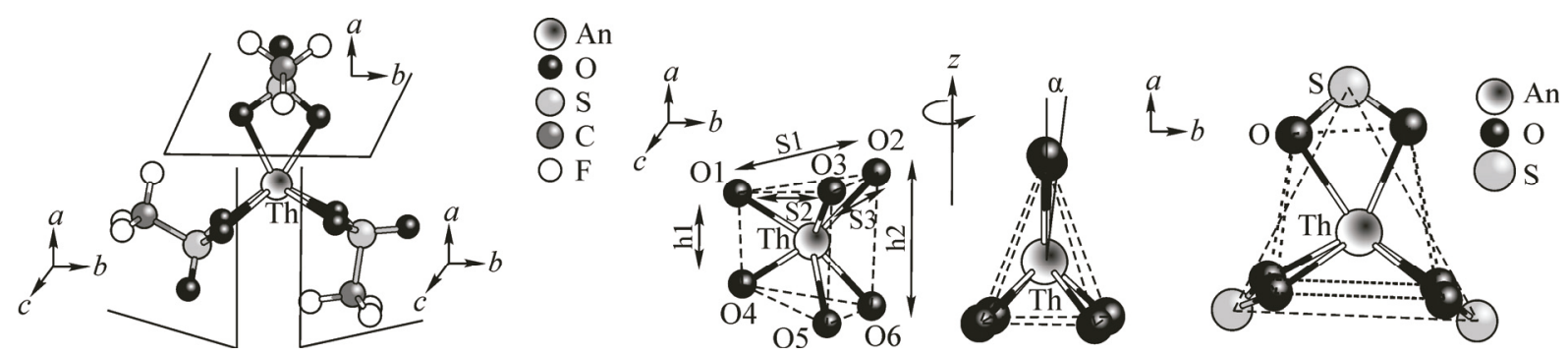

Scheme 2. The thorium triflate $\mathrm{Th}(\mathrm{OTf})_{3}$ trigonal prism parameters

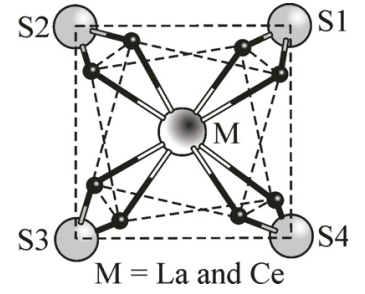

Scheme 3. The position of the sulfur atoms of $\mathrm{La}(\mathrm{OTf})_{4}$ and $\mathrm{Ce}(\mathrm{OTf})_{4}$ complexes

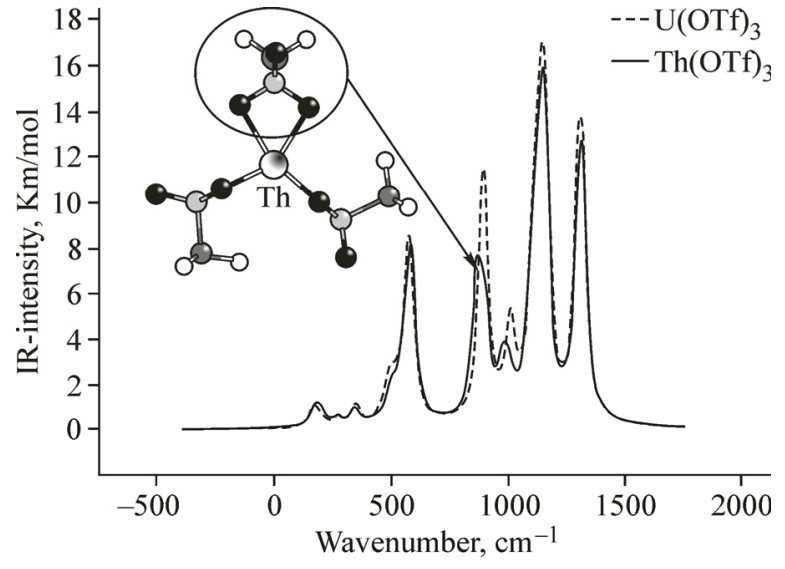

Fig. 1. Theoretical vibrational spectra of $\mathrm{U}(\mathrm{OTf})_{3}$ and $\mathrm{Th}(\mathrm{OTf})_{3}$

$h_{2}=3.55 \AA$ ) and a twist angle $(\alpha)$ equal to $3.13^{\circ}$. The difference between the ideal trigonal prism geometry of $\mathrm{U}(\mathrm{OTf})_{3}$ and the exceptional one of $\mathrm{Th}(\mathrm{OTf})_{3}$ is the presence of a peak near to $907 \mathrm{~cm}^{-1}$. This vibration can be assigned to the stretching vibration of the OTf ligand that is located in the vertical surface (Scheme 2 and Fig. 1).

Quantum descriptors. As previously mentioned, the actinide and lanthanide triflates are used as catalyst in a variety of chemical reactions. The knowledge of the descriptors $\eta, \mu$ and $\omega$ of the DFT conceptual is required, the calculated values of these latter are found in Table 2.

A strong Lewis acidity, as well as catalytic activity [27], could be predicted for these compounds. Chemical hardness is associated with the stability and reactivity of a chemical system. On the basis of frontier molecular orbitals, chemical hardness corresponds to the gap between the HOMO and LUMO. Chemical hardness was calculated as the method in [28-33].

Overall reactivity descriptors $(\mathrm{eV})$ of $\mathrm{M}(\mathrm{OTf})_{3}$, where $\mathrm{M}=\mathrm{La}, \mathrm{Ce}, \mathrm{Nd}, \mathrm{Eu}, \mathrm{Gd}, \mathrm{Er}, \mathrm{Yb}, \mathrm{Lu}, \mathrm{Th}, \mathrm{U}, \mathrm{Np}, \mathrm{Pu}, \mathrm{Am}, \mathrm{Cm}, \mathrm{Bk}$, and $\mathrm{No}$

\begin{tabular}{c|c|c|c|c|c||c|c|c|c|c|c}
\hline $\mathrm{Ln}$ & $\mu$ & $\eta$ & $\mathrm{w}$ & $E_{\text {номо }}$ & $E_{\text {LUмо }}$ & $\mathrm{An}$ & $\mu$ & $\eta$ & $\mathrm{w}$ & $E_{\text {номо }}$ & $E_{\text {LUмо }}$ \\
\hline $\mathrm{La}$ & -6.15 & 4.65 & 4.07 & -8.48 & -3.83 & $\mathrm{Th}$ & -6.10 & 5.47 & 3.40 & -8.84 & -3.37 \\
$\mathrm{Ce}$ & -6.62 & 3.78 & 5.78 & -8.51 & -4.72 & $\mathrm{U}$ & -4.02 & 0.70 & 11.54 & -4.37 & -3.67 \\
$\mathrm{Nd}$ & -6.91 & 3.36 & 7.09 & -8.59 & -5.22 & $\mathrm{~Np}$ & -4.48 & 1.00 & 10.03 & -4.98 & -3.98 \\
$\mathrm{Eu}$ & -6.36 & 4.59 & 4.41 & -8.66 & -4.07 & $\mathrm{Pu}$ & -5.08 & 1.31 & 9.86 & -5.74 & -4.43 \\
$\mathrm{Gd}$ & -5.98 & 5.10 & 3.50 & -8.53 & -3.43 & $\mathrm{Am}$ & -5.80 & 1.64 & 10.25 & -6.62 & -4.98 \\
$\mathrm{Er}$ & -5.59 & 5.92 & 2.64 & -8.55 & -2.63 & $\mathrm{Cm}$ & -6.27 & 2.25 & 8.70 & -7.40 & -5.15 \\
$\mathrm{Yb}$ & -5.51 & 5.82 & 2.61 & -8.43 & -2.60 & $\mathrm{Bk}$ & -6.86 & 1.72 & 13.68 & -7.72 & -6.00 \\
$\mathrm{Lu}$ & -5.74 & 5.80 & 2.84 & -8.64 & -2.84 & $\mathrm{No}$ & -5.43 & 5.99 & 2.46 & -8.43 & -2.44
\end{tabular}


Main geometry parameters of $\mathrm{M}(\mathrm{OTf})_{4}$ compounds, where $\mathrm{M}=\mathrm{La}, \mathrm{Ce}, \mathrm{Lu}, \mathrm{Th}, \mathrm{U}$, and $\mathrm{Pu} ; \mathrm{O} *$ is free atom

\begin{tabular}{l|c|c|c|c|c|c||c|c|c|c|c|c|c}
\hline Parameter & $\mathrm{La}$ & $\mathrm{Ce}$ & $\mathrm{Lu}$ & $\mathrm{Th}$ & $\mathrm{U}$ & $\mathrm{Pu}$ & Parameter & $\mathrm{La}$ & $\mathrm{Ce}$ & $\mathrm{Lu}$ & $\mathrm{Th}$ & $\mathrm{U}$ & $\mathrm{Pu}$ \\
\hline $\mathrm{M}-\mathrm{O}, \AA$ & 2.58 & 2.44 & 2.35 & 2.46 & 2.38 & $2.42-2.36$ & $\angle \mathrm{OMO}$, deg. & 56 & 59 & 60 & 58 & 60 & 60 \\
$\mathrm{M}-\mathrm{O}^{*}, \AA$ & 4.28 & 4.17 & 3.94 & 4.25 & 4.16 & 4.20 & $\angle$ SMS, deg. & 90 & 90 & 97 & 100 & 100 & 102 \\
$\mathrm{M}-\mathrm{S}, \AA$ & 3.17 & 3.05 & 2.93 & 3.09 & 3.01 & 3.02 & & & & &
\end{tabular}

The electrophilicity values listed in Table 2 show that $\mathrm{Bk}(\mathrm{OTf})_{3}$ has a greater ability to remove electrons, this indicates that $\mathrm{Bk}(\mathrm{OTf})_{3}$ has a strong electrophilicity. Based on the values of the hardness and electrophilicity, $\mathrm{Nd}(\mathrm{OTf})_{3}, \mathrm{Ce}(\mathrm{OTf})_{3}, \mathrm{Bk}(\mathrm{OTf})_{3}$ and $\mathrm{U}(\mathrm{OTf})_{3}$ are soft Lewis acids, $\mathrm{Th}(\mathrm{OTf})_{3}$ and $\mathrm{No}(\mathrm{OTf})_{3}$ are the hardest of all studied series (Table 2). According to the reactivity scale established following the electronic chemical potential $(\mu)[26], \mathrm{U}(\mathrm{OTf})_{3}$ and $\mathrm{Yb}(\mathrm{OTf})_{3}$ are the most reactive and $\mathrm{Nd}(\mathrm{OTf})_{3}$ and $\mathrm{Bk}(\mathrm{OTf})_{3}$ are the less reactive.

The structural arrangement of lanthanide and actinide triflates $\mathrm{M}(\mathrm{OTf})_{4}$. The main objective of this theoretical approach is to provide informations on the structural properties of $\mathrm{M}(\mathrm{OTf})_{4}(\mathrm{M}=\mathrm{La}$, $\mathrm{Ce}, \mathrm{Lu}, \mathrm{Th}, \mathrm{U}$ and $\mathrm{Pu})$, especially for $\mathrm{Ce}(\mathrm{OTf})_{4}, \mathrm{Th}(\mathrm{OTf})_{4}$ and $\mathrm{U}(\mathrm{OTf})_{4}$, where the X-ray structure determination was not performed [34-36].

As in $\mathrm{M}(\mathrm{OTf})_{3}$, the ligand OTf prefers the bidentate position. The length of the $\mathrm{M}-\mathrm{O}$ in the case of $\mathrm{La}(\mathrm{OTf})_{4}$ and $\mathrm{Lu}(\mathrm{OTf})_{4}$ binding is longer than $\mathrm{La}(\mathrm{OTf})_{3}$, and $\mathrm{Lu}(\mathrm{OTf})_{3}(2.49 \AA$ and $2.29 \AA)$ [ 15 ], respectively. Furthermore, this bond is shorter in the case of $\mathrm{Ce}(\mathrm{OTf})_{4}$ and $\mathrm{U}(\mathrm{OTf})_{4}$ for $\mathrm{Ce}(\mathrm{OTf})_{3}$ and $\mathrm{U}(\mathrm{OTf})_{3}[15]$ (Tables 1 and 3). The geometries of $\mathrm{La}(\mathrm{OTf})_{4}$ and $\mathrm{Ce}(\mathrm{OTf})_{4}$, have high regularity; namely SMS angles and distances between the metal and the sulfur atoms $(\mathrm{M}-\mathrm{S})$ are identical in each complex, the four sulfur atoms on the vertices of a square (Scheme 3).

Molecular orbital analysis. It seems useful to discuss the composition of the molecular orbitals. The analysis shows that the highest occupied molecular orbital of the $\mathrm{Th}(\mathrm{OTf})_{3}$ has ligand character, the contribution of oxygen is located in the beta spin. The participation by $6 d$ orbital in the case of thorium triflate is situated at the alpha orbital spin, the compounds $\mathrm{An}(\mathrm{OTf})_{3}$ in which $\mathrm{An}=\mathrm{U}, \mathrm{Np}, \mathrm{Pu}$, $\mathrm{Bk}, \mathrm{Am}$, and $\mathrm{Cm}$ contribute to the covalent bond by $5 f$ orbital localized on alpha and beta spin. The loss of an electron from the highest occupied molecular orbital (HOMO) of Th(OTf $)_{3}$, significantly improves its energy gap and stabilizes its structure (Scheme 4). A delocalization of the frontier orbital on all the atoms is observed in the case of $\mathrm{No}(\mathrm{OTf})_{3}$. $\mathrm{No}(\mathrm{OTf})_{3}$ is able to gain an electron to improve its energetic gap (Scheme 4). The addition of one ligand OTf to Th(OTf $)_{3}$ makes it more stable and improves its energy gap $(5.084 \mathrm{eV})$ compared to the other complexes $\mathrm{M}(\mathrm{OTf})_{4}$, where $\mathrm{M}=\mathrm{La}, \mathrm{Ce}, \mathrm{Lu}$, $\mathrm{U}$, and $\mathrm{Pu}$. The contribution of the $5 f$ orbital in HOMO and LUMO is $100 \%$ for $\mathrm{U}(\mathrm{OTf})_{4}$ and $\mathrm{Pu}(\mathrm{OTf})_{4}$. For other compounds $\mathrm{M}(\mathrm{OTf})_{4}$, where $\mathrm{M}=\mathrm{La}, \mathrm{Ce}, \mathrm{Lu}$, and $\mathrm{Th}$, the oxygen character ( the $2 p$ orbital) is predominant in the HOMO, while the LUMO is totally metallic (the $5 f$ orbital) (Scheme 4). In order to better understand the contribution of the $5 f$ orbital in the bonding in $\operatorname{An}(\mathrm{OTf})_{3}$, as for the $\operatorname{Ln}(\mathrm{OTf})_{3}$ [26] we performed DFT calculations and treated valence electrons (small, medium, and big core) for the uranium and thorium triflates, as they represent the ideal and exceptional geometries. Whatever the type of calculation (large, medium, or small core) (Table 4), we notice that the atomic orbital population for both $\mathrm{U}$ and $\mathrm{Th}$ is practically the same; with a slight difference of $10^{-3}$ order. This justifies our choice of computing with medium core (Table 5). Comparing the populations of atomic orbitals provides precious information, namely, in all complexes occupation of the orbital $6 \mathrm{~d}$ by an electron was observed, except for $\mathrm{Th}(\mathrm{OTf})_{3}$ in which the two electrons are more involved in the thorium-oxygen bond. The $5 f$ orbital of $\mathrm{Th}(\mathrm{OTf})_{3}$ is less populated compared to the rest of the compounds, and this shows that this orbital does not contribute in $\mathrm{Th}-\mathrm{O}$ bond and explains exception observed (Table 5).

Topological study of electron density: QTAIM analysis. The Quantum Theory of Atoms in Molecules (QTAIM) of Bader [37], states that there is one bond critical point (BCP) between each pair of atoms and a chemical bonding interactions may be characterized and classified according to the 


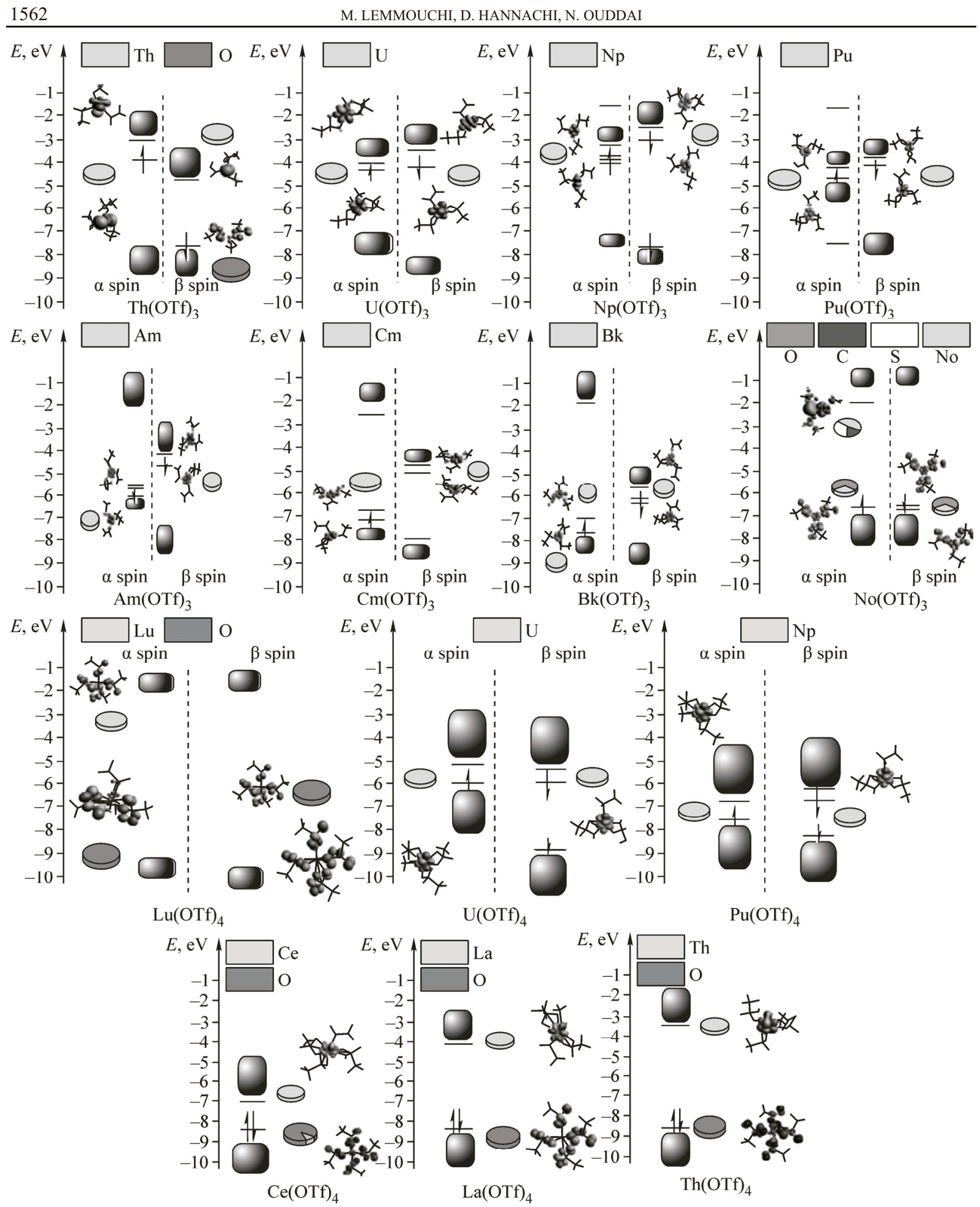

Scheme 4. DFT molecular orbital diagrams of $\mathrm{M}(\mathrm{OTf})_{n}$ where $(\mathrm{M}=\mathrm{La}, \mathrm{Ce}, \mathrm{Lu}, \mathrm{Th}, \mathrm{U}, \mathrm{Np}, \mathrm{Pu}, \mathrm{Am}, \mathrm{Cm}, \mathrm{Bk}$, and No) and $n=3,4$

properties of the electron and energy densities at these BCP [26]. The topological properties of electron density $\rho(r)$, Laplacian $\nabla^{2} \rho(r)$, the ratio $(|V| / G)$ (where $(V(r)$ is the electronic potential energy density and $G(r)$ is kinetic energy density), the total electronic energy density $H(r)$ are summarized in Table 6. Depending on the sign of the total energy density of electrons $H(r)$, Espinosa and Al divided the atomic interaction into three categories [38-42]. 
Population of the atomic orbital of $\mathrm{Th}(\mathrm{OTf})_{3}$ and $\mathrm{U}(\mathrm{OTf})_{3}$ with small, medium, and large core calculations

\begin{tabular}{l|c|c|c|c}
\hline \multicolumn{1}{c|}{ Complex } & $s$ & $p$ & $d$ & $f$ \\
\hline Th(OTf $)_{3}$ small core Th & 1.3139 & 3.0091 & 0.9776 & 0.3799 \\
Th(OTf $)_{3}$ medium core Th & 1.3131 & 3.0090 & 0.9778 & 0.3795 \\
Th(OTf $)_{3}$ large core Th & 1.3140 & 3.0091 & 0.9775 & 0.3799 \\
U(OTf $)_{3}$ small core U & 1.1451 & 2.9691 & 0.4239 & 2.1303 \\
U(OTf $)_{3}$ medium core U & 1.1455 & 2.9696 & 0.4245 & 2.1305 \\
U(OTf $)_{3}$ large core U & 1.1450 & 2.9692 & 0.4239 & 2.1309
\end{tabular}

Population of the atomic orbital $\mathrm{An}(\mathrm{OTf})_{3}$ with medium core calculation

\begin{tabular}{l|c|c|c|c}
\hline \multicolumn{1}{c|}{ Complex } & $s$ & $p$ & $d$ & $f$ \\
\hline $\mathrm{Th}(\mathrm{OTf})_{3}$ & 1.3131 & 3.0090 & 0.9778 & 0.3795 \\
$\mathrm{U}(\mathrm{OTf})_{3}$ & 1.1450 & 2.9696 & 0.4245 & 2.1305 \\
$\mathrm{~Np}(\mathrm{OTf})_{3}$ & 1.1138 & 2.9890 & 0.4161 & 3.1862 \\
$\mathrm{Pu}(\mathrm{OTf})_{3}$ & 1.1018 & 3.0049 & 0.4098 & 4.1861 \\
$\mathrm{Am}(\mathrm{OTf})_{3}$ & 1.1119 & 3.0108 & 0.4042 & 5.2117 \\
$\mathrm{Cm}(\mathrm{OTf})_{3}$ & 1.1110 & 3.0061 & 0.4117 & 6.1952 \\
$\mathrm{Bk}(\mathrm{OTf})_{3}$ & 1.1098 & 3.0091 & 0.3939 & 6.1934 \\
$\mathrm{No}(\mathrm{OTf})_{3}$ & 1.0946 & 3.0575 & 0.2332 & 7.0107
\end{tabular}

T a b l e 6

QTAIM calculated values of $\mathrm{M}(\mathrm{OTf})_{n}$, where $\mathrm{M}=\mathrm{La}, \mathrm{Ce}, \mathrm{Lu}, \mathrm{Th}, \mathrm{U}, \mathrm{Np}, \mathrm{Pu}, \mathrm{Am}, \mathrm{Cm}, \mathrm{Bk}$, and No; $n=3,4$

\begin{tabular}{l|l|c|c|c|c||l|l|l|l|l|c}
\hline \multicolumn{1}{c|}{ Complex } & Bond & $\rho(r)$ & $\nabla^{2} \rho(r)$ & $|V| / G$ & $H(r)$ & Complex & Bond & $\rho(r)$ & $\nabla^{2} \rho(r)$ & $|V| / G$ & $H(r)$ \\
\hline $\mathrm{Th}(\mathrm{OTf})_{3}$ & $\mathrm{Th}-\mathrm{O}$ & 0.1112 & 0.1551 & 1.3726 & -0.0226 & $\mathrm{No}(\mathrm{OTf})_{3}$ & $\mathrm{No}-\mathrm{O}$ & 0.0996 & 0.1366 & 1.2974 & -0.0144 \\
$\mathrm{U}(\mathrm{OTf})_{3}$ & $\mathrm{U}-\mathrm{O}$ & 0.1000 & 0.2123 & 1.2483 & -0.0146 & $\left.\mathrm{La}_{(\mathrm{OTf}}\right)_{4}$ & $\mathrm{La}-\mathrm{O}$ & 0.0798 & 0.1448 & 1.0032 & -0.0941 \\
$\mathrm{~Np}(\mathrm{OTf})_{3}$ & $\mathrm{~Np}-\mathrm{O}$ & 0.0989 & 0.1977 & 1.2245 & -0.0175 & $\mathrm{Ce}(\mathrm{OTf})_{4}$ & $\mathrm{Ce}-\mathrm{O}$ & 0.0759 & 0.1886 & 1.0743 & -0.0038 \\
$\mathrm{Pu}(\mathrm{OTf})_{3}$ & $\mathrm{Pu}-\mathrm{O}$ & 0.0953 & 0.1366 & 1.2974 & -0.0172 & Th(OTf $)_{4}$ & $\mathrm{Th}-\mathrm{O}$ & 0.0887 & 0.1311 & 1.3311 & -0.0162 \\
$\mathrm{Am}(\mathrm{OTf})_{3}$ & $\mathrm{Am}-\mathrm{O}$ & 0.0911 & 0.1983 & 1.2570 & -0.0171 & $\mathrm{U}(\mathrm{OTf})_{4}$ & $\mathrm{U}-\mathrm{O}$ & 0.1034 & 0.1720 & 1.3023 & -0.0185 \\
$\mathrm{Cm}(\mathrm{OTf})_{3}$ & $\mathrm{Cm}-\mathrm{O}$ & 0.1014 & 0.1776 & 1.2910 & -0.0182 & Pu(OTf $)_{4}$ & $\mathrm{Pu}-\mathrm{O}$ & 0.0984 & 0.1714 & 1.2817 & -0.0168 \\
$\mathrm{Bk}(\mathrm{OTf})_{3}$ & $\mathrm{Bk}-\mathrm{O}$ & 0.0998 & 0.1896 & 1.2778 & -0.0182 & & & & &
\end{tabular}

According to the values of Table 6 , the critical points between the metal and the oxygen of the OTf groups are characterized relatively by low values of $\rho(r)$, the $H(r)$ has negative values and the ratio $|V| / G$ values are less than two. These parameters of critical points BCP correspond to intermediate interactions for all the studied triflate complexes. The positive values of $\nabla^{2} \rho(r)$ are related to the binding order. The greater value of $\rho(r)$ corresponds to the strongest bond [43], this is in agreement with the results found with the quantum descriptors for $\mathrm{Th}(\mathrm{OTf})_{3}$ and $\mathrm{U}(\mathrm{OTf})_{4}$.

Lanthanide triflate intramolecular rearrangements. Description of $\operatorname{Ln}(\mathrm{OTf})_{3}$ skeleton, where $\mathbf{L n}=\mathbf{L a}, \mathbf{C e}, \mathbf{G d}, \mathbf{Y b}$, and $\mathbf{L u}$. The skeleton of lanthanide triflates $\operatorname{Ln}(\mathrm{OTf})_{3}$ is formed by three bidentate OTf groups related to the central metal; in a way as to form two conformers in the trigonal prism geometry (TP) [ 15 ]. The skeleton is characterized by two dihedral twist angles notated $\theta$ and $\varphi$ (Scheme 5). Quantum computing has shown that the conformer 2 is more stable than the conformer 1 [15]. The compound $\mathrm{Yb}(\mathrm{OTf})_{3}$ makes the exception with its $\theta$ and $\varphi$ angles, as shown in Table 7. Our results give that the staggered geometry is the stable one. The conformer 1 (Conf1) corresponds to the pseudo-eclipsed form; to gain insights about this offset we measure the dihedral twist angle $\beta=$ $=\mathrm{C}-\mathrm{S}-\mathrm{S}-\mathrm{C}$ for each complex. The pseudo-eclipsed conformation shows a deviation of the $\beta$ angle between two triflate groups. Our calculations show that $\mathrm{Yb}(\mathrm{OTf})_{3}$ has the highest value of $\beta$, and $\mathrm{Lu}(\mathrm{OTf})_{3}$ presents the smallest $\alpha$ value (Table 8 ).

Mechanistic study. The passage Conf1 $\leftrightarrow$ Conf 2 corresponds to the rotation of the ligand OTf around the Ln-S bond with a twist angle $\omega$. The conformational analysis based on $\omega$ angle involves varying the value of the dihedral angle in regular steps from $\omega 1$ (value of Conf1) to $\omega 2$ (value of Conf2). The results are presented in Table 9. The energy difference $\Delta G$ between the intermediate state (TS) and the final state (conf2) in the intramolecular rearrangement of $\mathrm{Lu}(\mathrm{OTf})_{3}$ is equal to $3.54 \mathrm{Kcal} / \mathrm{mol}$, and this value is close to those of $\mathrm{La}(\mathrm{OTf})_{3}$ and $\mathrm{Gd}(\mathrm{OTf})_{3}$. For the ytterbium triflate, the $\Delta G$ is five times higher than those of the remaining compounds of the series. The $\omega$ angle of the transition state is equal to $113^{\circ}$, which correspond to an imaginary peak at $-52 \mathrm{~cm}^{-1}$ (Fig. 2). 


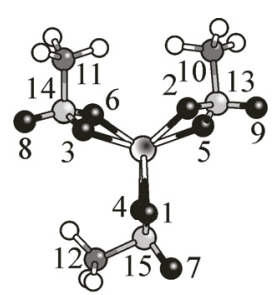

Conformer 1(Conf1)

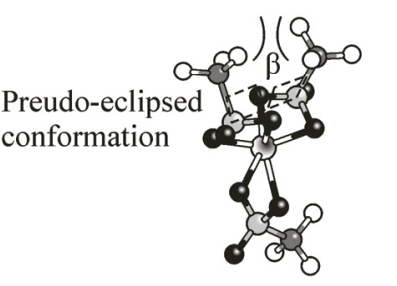

Scheme 5. Conformers La(OTf $)_{3}$

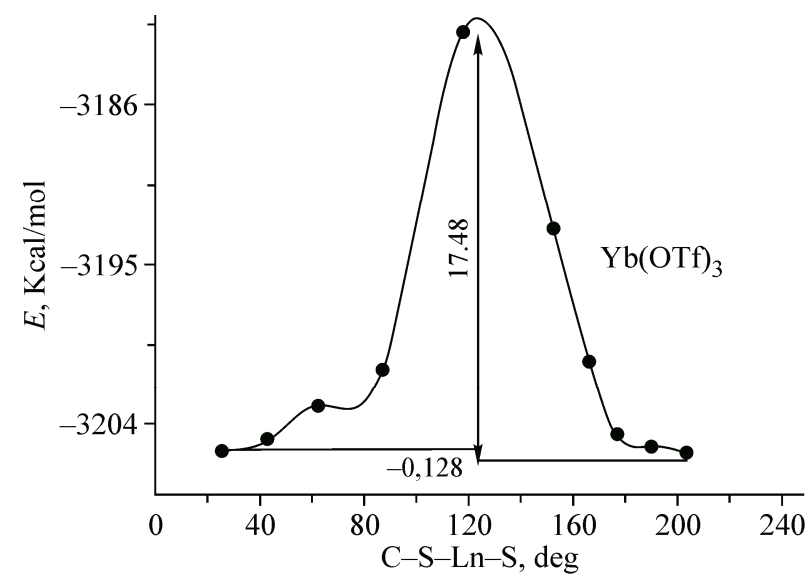

Fig. 2. Variation of the potential energy surface according to the $\omega$ angle of $\mathrm{Yb}(\mathrm{OTf})_{3}$

T a b l e 7

Dihedral angles measuring of $\mathrm{Ln}(\mathrm{OTf})_{3}$, where $\mathrm{Ln}=\mathrm{La}, \mathrm{Ce}, \mathrm{Gd}, \mathrm{Yb}$, and $\mathrm{Lu}$.

The bold values correspond to conformer 2

\begin{tabular}{|c|c|c|c|c|c|}
\hline Parameter & $\mathrm{La}(\mathrm{OTf})_{3}$ & $\mathrm{Lu}(\mathrm{OTf})_{3}$ & $\mathrm{Ce}(\mathrm{OTf})_{3}$ & $\mathrm{Gd}(\mathrm{OTf})_{3}$ & $\mathrm{Yb}(\mathrm{OTf})_{3}$ \\
\hline \multicolumn{6}{|c|}{$\theta$, deg. } \\
\hline $\mathrm{C} 10-\mathrm{S} 13-\mathrm{Ln}-\mathrm{S} 14$ & $339, \mathbf{1 8 0}$ & $21, \mathbf{1 8 1}$ & $340, \mathbf{1 8 0}$ & $339, \mathbf{1 8 2}$ & 26,203 \\
\hline $\mathrm{C} 11-\mathrm{S} 14-\mathrm{Ln}-\mathrm{S} 15$ & $165, \mathbf{1 8 0}$ & $198, \mathbf{1 8 0}$ & $169, \mathbf{1 8 0}$ & $164, \mathbf{1 8 2}$ & $206, \mathbf{2 0 2}$ \\
\hline $\mathrm{C} 12-\mathrm{S} 15-\mathrm{Ln}-\mathrm{S} 13$ & $175, \mathbf{1 8 0}$ & $193, \mathbf{1 8 1}$ & 172,179 & $170, \mathbf{1 8 2}$ & $203, \mathbf{2 0 3}$ \\
\hline $\mathrm{C} 10-\mathrm{S} 13-\mathrm{Ln}-\mathrm{S} 15$ & $159, \quad \mathbf{0}$ & $202, \quad 2$ & $159, \quad \mathbf{0}$ & $159, \quad \mathbf{0}$ & $208, \quad 29$ \\
\hline
\end{tabular}

\begin{tabular}{|c|c|c|c|c|c|}
\hline \multicolumn{6}{|c|}{$\varphi$, deg. } \\
\hline $9-\mathrm{S} 13-\mathrm{Ln}-\mathrm{S} 14$ & $159, \mathbf{1 8 0}$ & $202, \quad 2$ & 159 & $158, \mathbf{1 8 2}$ & 207 \\
\hline $8-\mathrm{S} 14-\mathrm{Ln}-\mathrm{S} 15$ & $344, \quad \mathbf{0}$ & 18 & 348 & 343 & 26 \\
\hline$-\mathrm{Ln}-\mathrm{S} 13$ & 355 & 13 , & 353 & 351 , & 24, \\
\hline $9-\mathrm{S} 13-\mathrm{Ln}-\mathrm{S} 15$ & $338, \mathbf{1 8 0}$ & $22, \mathbf{1 8 2}$ & $339, \mathbf{1 8 0}$ & $338, \mathbf{1 8 2}$ & 29,2 \\
\hline
\end{tabular}

T a b 1 e 8

T a b 1 e 9

$\beta$ and $\alpha$ (deg.) values for $\mathrm{Ln}(\mathrm{OTf})_{3}$

\begin{tabular}{c|c|c|c|c|c}
\hline & $\mathrm{La}(\mathrm{OTf})_{3}$ & $\mathrm{Ce}(\mathrm{OTf})_{3}$ & $\mathrm{Gd}(\mathrm{OTf})_{3}$ & $\mathrm{Lu}_{(\mathrm{OTf})_{3}}$ & $\mathrm{Yb}(\mathrm{OTf})_{3}$ \\
\hline$\beta$ & 33 & 29 & 34 & 36 & 49 \\
$\alpha$ & 180 & 179 & 175 & 119 & 178
\end{tabular}

The Gibbs energy, kcal/mol

\begin{tabular}{c|c|c|c|c}
\hline $\mathrm{Ln}(\mathrm{OTf})_{3}$ & $G$ Conf1 & $G_{\mathrm{TS}}$ & $G_{\mathrm{Conf} 2}$ & $\Delta G_{\mathrm{TS}-\mathrm{Conf} 2}$ \\
\hline $\mathrm{La}(\mathrm{OTf})_{3}$ & -3642.880 & -3640.700 & -3643.180 & 2.480 \\
$\mathrm{Ce}(\mathrm{OTf})_{3}$ & -3645.185 & -3644.818 & -3645.519 & 0.701 \\
$\mathrm{Gd}(\mathrm{OTf})_{3}$ & -3834.830 & -3832.520 & -3835.213 & 2.693 \\
$\mathrm{Yb}(\mathrm{OTf})_{3}$ & -3533.047 & -3515.550 & -3533.532 & 17.982 \\
$\mathrm{Lu}(\mathrm{OTf})_{3}$ & -3618.460 & -3615.390 & -3618.930 & 3.540
\end{tabular}

\section{CONCLUSIONS}

Quantum calculations on actinide triflates $\mathrm{An}(\mathrm{OTf})_{3}$ found that their geometry is similar to lanthanide triflates $\operatorname{Ln}(\mathrm{OTf})_{3}$, where the OTf ligand is bidentate. The values of side ridge $(s)$ and intertriangular separation $(h)$ explain the exceptionality of the $\mathrm{Th}(\mathrm{OTf})_{3}$ structure.

The QTAIM analysis showed that the $\mathrm{Th}(\mathrm{OTf})_{3}$ contributes greatly with $5 d$ orbital in $\mathrm{Th}-\mathrm{O}$ bond and gives the highest calculated hardness. The electrophilicity calculated values for the $\mathrm{M}(\mathrm{OTf})_{3}$ series, where $\mathrm{M}=\mathrm{Nd}, \mathrm{Ce}, \mathrm{U}$ and $\mathrm{Bk}$ agree with the range of strong Lewis acids. 
For ytterbium $\mathrm{Yb}(\mathrm{OTf})_{3}$ and uranium $\mathrm{U}(\mathrm{OTf})_{3}$ a strong acidity is predicted, so that these two compounds are classified as potential catalysts. Within the family of lanthanide triflates $\operatorname{Ln}(\mathrm{OTf})_{3}$, where $\mathrm{Ln}=\mathrm{La}, \mathrm{Ce}, \mathrm{Gd}, \mathrm{Yb}$ and $\mathrm{Lu}$, our study shows the existence of two conformations: pseudoeclipsed and staggered forms. For all compounds the two geometric forms are in equilibrium, except for the ytterbium triflate where both forms are stable and can be isolated. The peculiarity observed in the latter explains its high catalytic activity.

\section{REFERENCES}

1. Piguet C., Bünzli J.C.G. // Chem. Soc. Rev. - 1999. - 28. - P. 347 - 358.

2. Handbook on the Physics and Chemistry of Rare Earths. Lanthanides/Actinides: Chemistry. Eds.: K.A. Gschneidner Jr., L. , G.R. Chopin, G.H. Lander - Elsevier Science, 1994. - P. 18.

3. Kobayashi S. // Synlett. - 1994. - P. 689. b) Edelmann F.T. // New J. Chem. - 1995. - 19. - P. 535. c) Schumann H., Meese-Marktscheffel J.A., Dietrich A., Görlitz F.H. // J. Organomet. Chem. - 1992. - 299. - P. 430.

4. Lawrance G.A. // Chem. Rev. - 1986. - 17. - P. 86.

5. Actinides and Fission Products Partitioning and Transmutation, Status and Assessment Report. Proc. 5th Int. Information Exchange Meeting. - Mol, Belgium, 1998. NEA/OECD, Paris, 1999. - P. 25 - 27.

6. Nash K.L. // Solvent Extr. Ion Exch. - 1993. - 11. - P. 729. b) Handbook on the Physics and Chemistry of Rare Earths. Lanthanides/Actinides: Chemistry. Eds.: K.A. Gschneidner Jr., L. Eyring, G.R. Chopin, G.H. Lander - Amsterdam: Elsevier Science, 1994. - P. 197.

7. Nocton G., Burdet F., Pécaut J., Mazzanti M. // Angew. Chem. Int. Ed. - 2007. - 46. - P. 7574 - 7578.

8. Matonic J.H., Scott B.L., Neu M.P. // Inorg. Chem. - 2001. - 40. P. - 2638 - 2639. b) Lindqvist-Reis P., Apostolidis C., Rebizant J., Morgenstern A., Klenze R., Walter O., Fanghänel T., Haire R.G. // Angew. Chem. Int. Ed. - 2007. - 46. - P. 919 - 922. c) Skanthakumar S., Antonio M.R., Wilson R.E., Soderholm L. // Inorg. Chem. - 2007. - 46. - P. 3485 - 3491.

9. Cotton S.A. In: Lanthanide and Actinide Chemistry - Inorganic Chemistry. - John Wiley \& Sons, 2006. - P. 193.

10. Lyczko K. et al. // Inorg. Chem. Commun. - 2012. - 24. - P. $234-236$.

11. Berthet J.C., Lance M., Nierlich M., Ephritikhine M. // J. Inorg. Chem. - 1999. - P. 2005 - 2007.

12. Baerends E.J., Ellis D.E., Ros P. // Chem. Phys. - 1973. - 2. - P. 41.

13. Perdew J.P., Chevary J.A., Vosko S.H., Jackson K.A., Pederson M.R., Singh D.J., Fiolhais C. // Phys. Rev. B. - 1992. - 46. - P. 6671.

14. Van Lenthe E., Ehlers A., Baerends E.J. // J. Chem. Phys. - 1999. - 110. - P. 8943.

15. Hannachi D., Ouddai N., Chermette H. // Dalton Trans. - 2010. - 39. - P. $3673-3680$.

16. Shamov G.A. // Inorg. Chem. - 2012. - 51. - P. 6507 - 6516

17. Ingram K.I.M., Tassell M.J., Gaunt A.J., Kaltsoyannis N. // Inorg. Chem. - 2008. - 47. - P. $7824-7833$.

18. Gaunt A.J., Reilly S.D., Enriquez A.E., Scott B.L., Ibers J.A., Sekar P., Ingram K.I.M., Kaltsoyannis N., Neu M.P. // Inorg. Chem. - 2008. - 47, N 1. - P. $29-41$.

19. Graves C.R., Schelter E.J., Cantat T., Scott B.L., Kiplinger J.L. // Organometallics. - 2008. - 27. - P. 5371 5378.

20. Berthet J.C., Nierlich M., Ephritikhine M. // Angew. Chem., Int. Ed. - 2003. - 42. - P. 1952 - 1954.

21. Berthet J.C., Lance M., Nierlich M., Ephritikhine M. // J. Chem. Soc. Chem. Commun. - 1998. - P. 1373.

22. Allred A.L., Rochow E.G. // J. Org. Chem. - 1949. - 5. - P. 264.

23. Lakehal S., Ouddai N., Hannachi D., Bououdina M. // Int. J. Quantum Chem. - 2012. - P. 24339.

24. Pearson R.G. // Coord. Chem. Rev. - 1990. - 100. - P. 403.

25. Geerlings P., De Proft F., Langenaeker W.// Chem. Rev. - 2003. - 103. - P. 1793.

26. Parr P.G., Pearson R.G. // J. Am. Chem. Soc. - 1983. - 105. - P. 7512.

27. Parr R.G., Szentpaly L., Liu S. // J. Am. Chem. Soc. - 1999. - 121. - P. 1922.

28. Koopmans T. // Physica. - 1933. - 1. - P. 104.

29. Liu S. // J. Chem. Sci. - 2005. - 117. - P. 477.

30. Lyczko K. et al. // Inorg. Chem. Commun. - 2012. - 24. - P. $234-236$.

31. Khalafi-Nezhad A., Alamdari R.F. // Tetrahedron. - 2001. - 57. - P. 6805 - 6807.

32. Mendoza-Wilson A.M., Ávila-Quezada G.D., Balandrán-Quintana R.R., Glossman-Mitnik D., Ruiz-Cruz S. // J. Mol. Struct.: THEOCHEM. - 2009. - 897. - P. 6 - 11.

33. Marabello D., Bianchi R., Gervasio G., Cargnoni F. // Acta Crystallogr. - 2004. - 60. - P. 494.

34. Bader R.F.W., Essen H.J. // J. Chem. Phys. - 1984. - 80. - P. 1943 - 1960.

35. Espinosa A., Alkorta L., Elguero J., Molins E. // J. Chem. Phys. - 2002. - 117. - P. 5529.

36. Egorova A.N., Tsirelson V.G. // Russ. J. Inorg. Chem. - 2006. - 51. - P. 941.

37. Carles B., Costas M., Poblet J.M., Rohmer M. et al. // Inorg. Chem. - 1996. - 35. - P. 298.

38. Lein M., Szabo A., Kovacs A., Frenking G. // Faraday Discuss. - 2003. - 124. - P. 365 - 378. 